Journal of Research in Interprofessional

Practice and

Education

Vol. 1.3

December, 2010

\section{Through Teaching Are We Learning? Learning Through Teaching: Facilitating Interprofessional Education Experiences}

\author{
Ruby Grymonpre, PharmD, FCSHP; Cornelia van Ineveld, MD, FRCP(C); \\ Michelle Nelson, BRS, MA, BA; Amy De Jaeger, MA, BA (Hon); \\ Theresa Sullivan, BSc(OT), MA, Reg(MB); Fiona Jensen, RN, BsN, MsN; \\ Leah Weinberg, BPT, MSc, PhD; Jenneth Swinamer, BPT MSA(Health); \\ Ann Booth, MBA, BSc(OT)
}

\begin{abstract}
Background: Despite a growing recognition of the value of collaborative patientcentred practice (CPCP) there is a lack of evidence identifying key elements and approaches to an effective interprofessional (IP) education intervention for clinical team members. The present study was conducted to address the paucity of rigorous mixed methods research to address the question: Does clinician team facilitation and mentorship of senior pre-licensure learners participating in IP clinical placements improve team members' attitudes, knowledge, skills, and perceived behaviours in $\mathrm{CPCP}$ ?
\end{abstract}

Methods: Based on the assumption that Geriatric Day Hospital clinical teams were already highly collaborative, educational experiences for clinical team members were not designed a priori. Rather, the educational experience was grounded in Mezirow's transformative learning theory, proposing that learning is a process of becoming aware of one's assumptions and revising these assumptions based on critical self-reflection. The option to participate in structured observation and feedback by an external observer using the Team Observation Scale provided important and unique opportunities for team reflection. Using the Controlled Before and After (CBA) design, the Attitudes Toward Health Care Teams Scale (ATHCTS), Team Skills Scale (TSS), and Knowledge Questionnaire were administered pre- and post-clinical placements to intervention and control groups. Data were analyzed by descriptive, bivariate, and repeated measures ANOVA. Qualitative data (evaluation and self-reflective forms) were analyzed using content analysis techniques.

Results: Eleven IP clinical placements at 3 sites occurred between January 2007 and March 2008 (intervention $N=48$; control $N=7$ ). There was no significant change over time between intervention and control groups for the ATHCTS Quality of Care or Physician Centrality subscale scores, the TSS scores, or the Knowledge scores. Qualitative results suggested that participants were more aware of IP teaming, reflective of their own practice, and reported making changes in their own practice and mentorship of students as a result of their engagement in the study.

Conclusions: This study demonstrated the viability of using structured observation and feedback processes as a reflective learning exercise. Further research is required to help identify key approaches and elements to an effective IPE intervention in clinical practice.

Keywords: Interprofessional clinical placements; Clinical education; Team; Patientcentred Care; Geriatrics; Transformative learning 
201

Learning Through Teaching: Facilitating Interprofessional Education Experiences

Grymonpre, van Ineveld, Nelson, De Jaeger, Sullivan, Jensen, Weinberg, Swinamer, \& Booth

Journal of Research in Interprofessional Practice and Education

Vol. 1.3

December, 2010

\section{Introduction}

There is mounting awareness that collaborative patient-centred practice is a means to address complex and varied community and individual health and social care needs. In Canada, the 2002 Romanow report [1] and 2003 First Ministers' Accord on Health Care Renewal [2] recognized that the delivery of effective and efficient primary healthcare requires an integrated and interprofessional approach. Collaborative patient-centred practice was identified as one solution that may address emerging health and human resource issues and improve patient satisfaction and health outcomes. Romanow further emphasized that in order to achieve this goal, healthcare professionals require education and training that will prepare them to work together and share their expertise.

The concept of interprofessional education (IPE) has been explored for several decades. IPE began in the United Kingdom during the 1960s [3]. In North America, IPE programs have been developing over the last two decades. The Hartford Foundation-funded Geriatric Interdisciplinary Team Training (GITT) [4-9] and the Geriatric Education Centres (GEC), funded through the U.S. Bureau of Health Professions [10], created effective IPE initiatives throughout the United States.

In September 2004, Health Canada announced a call for proposals to support the development and implementation of Interprofessional Education for Collaborative Patient-Centred Practice (IECPCP) initiatives. The funding of 20 projects provided the stimulus for the development of a range of IECPCP initiatives across Canada. The Interprofessional Education in Geriatric Care (IEGC) project was one of the projects successfully funded through the IECPCP initiative.

Despite a growing body of IPE literature, there have been few rigorous evaluations of the benefit of IECPCP. In a review of 107 high quality studies published in the area of IPE between 1974 and 2003, Barr et al. [11] noted that 79\% of the studies targeted post-qualification health professions, using didactic teaching strategies such as workshops. Very few of these studies used mixed methods, and there was a noted lack of methodological rigor. The most recent Cochrane review [12] of studies measuring the effectiveness of IPE offered to practicing clinicians included 6 studies meeting the methodologically rigorous inclusion criteria. In this review, Reeves notes that given the dearth of research and heterogeneity of interventions, evidence is still lacking on the key approaches and elements to an effective IPE intervention in clinical practice. The present study was conducted to address the paucity of rigorous mixed method research specifically as it relates to the impact of IP clinical placements in geriatric settings on clinical team members' attitudes, knowledge, skills, and perceived behaviours.

\section{Project goal and research question}

The overarching goal of the IEGC project was to develop, implement, and evaluate interprofessional (IP) clinical placements for senior pre-licensure learners from 5 health professional programs (medicine, nursing, occupational therapy, pharmacy, physical therapy). The research component evaluated and explored the impact of the IEGC project on all participants: senior pre-licensure learners, clinical teams, clients, 
202

Learning Through Teaching: Facilitating Interprofessional Education Experiences

Grymonpre, van Ineveld, Nelson, De Jaeger, Sullivan, Jensen, Weinberg, Swinamer, \& Booth
Journal of Research in Interprofessional Practice and Education

Vol. 1.3

December, 2010 faculty, and the Steering Committee. Guided by the Joint Evaluation Team (JET) modified Kirkpatrick's Model of Educational Outcomes [13], the project sought to measure participant reaction, changes in knowledge and skills, attitudes/perceptions, and self-reported behaviour, as well as organizational change and benefit/burden on the client, as relevant. For the purposes of this IEGC study, focusing on clinical team members, five of the six educational outcomes were evaluated (reaction, changes in knowledge and skills, changes in attitudes/perceptions, self reported behaviour, and organizational change) using a mixed methods design [14].

The specific research question addressed in this article is: Does clinician team facilitation and mentorship of senior pre-licensure learners during interprofessional clinical placements improve team members' knowledge, attitudes, perceptions, and skills in collaborative patient-centred practice compared with a control group?

\section{Methods}

This project received the approval of the University of Manitoba Ethics Board as well as the appropriate institutional access/ethics review committees.

\section{Project setting and context}

The IEGC program was developed and delivered in partnership with the Winnipeg Regional Health Authority Geriatric Day Hospitals (GDH). GDHs provide interprofessional (IP) outpatient assessment and rehabilitation for complex, frail older adults. Older adults referred to GDHs must require the services of two or more health professionals. In these day hospitals, collaborative patient-centred care is the standard of practice, and team members routinely meet around individual patients, setting team goals and monitoring progress. These clinical sites have traditionally offered profession-specific clinical placements ${ }^{1}$ for senior pre-licensure learners ${ }^{2}$ at the University of Manitoba. However, no specific effort has been made to bring multiple learners from different professions into the clinical setting at the same time or to explicitly teach core competencies for collaborative patient-centred practice.

\section{IEGC educational experience for senior pre-licensure learners}

The IEGC educational experience for senior pre-licensure learners was offered within pre-existing clinical placements at intervention GDH sites when senior prelicensure learners from at least 3 of 5 different disciplines (medicine, pharmacy, nursing, occupational therapy, and physiotherapy) were present. This IP learning opportunity was not offered to students doing their placements at the control GDH site. The IEGC educational experience for senior pre-licensure learners involved 15 hours of IP learning activities over a 4-week "clinical block." The IP activities were embedded into the traditional uni-professional clinical placement learning activities, as required by each discipline. Specific activities included

- Icebreaker and wind-up activities: involved senior pre-licensure learners and all available clinical team members to emphasize the importance of social connection as the basis for developing rapport and trust between team members. These activities were facilitated by the 
Learning Through Teaching:

Facilitating Interprofessional Education Experiences

Grymonpre, van Ineveld, Nelson, De Jaeger, Sullivan, Jensen, Weinberg, Swinamer, \& Booth

Journal of Research in Interprofessional Practice and Education

Vol. 1.3

December, 2010

\section{Journal of Research in Interprofessional Practice and Education}

IEGC project staff (i.e., individuals hired by the IEGC project who were responsible for coordinating the educational interventions).

- Small group discussions: targeted seven collaborative competencies (disciplinary articulation, communication, conflict management, flexibility, leadership, team dynamics, goal setting). These competencies were originally outlined by Barr [15] and further synthesized by Curran [16].

- All senior pre-licensure learners and their discipline-specific mentors (i.e., preceptors) were required to attend, but the session was open to all other interested/available clinical team members. These sessions were facilitated by volunteer or appointed non-precepting clinical team members.

- IP shared-care planning sessions: after all senior pre-licensure learners completed their own uni-professional assessment, they met to negotiate an IP shared-care plan for the patient. These sessions were facilitated by two clinical team members who were not preceptors for any of the learners present.

Each IEGC clinical block was continually refined based on formative evaluation feedback from all participants (pre-licensure learners and clinical team members) immediately following each iteration of the clinical block offering.

IEGC educational experience for clinical team members (the intervention)

The IEGC educational experience for clinical team members was grounded in Mezirow's transformative learning theory [17]. Transformative learning theory proposes that learning is a process of becoming aware of one's assumptions and revising these assumptions based on critical self-reflection, which results in a change in a frame of reference. Mezirow further proposes that establishing certain learning circumstances will allow "transformative learners to move toward a frame of reference that is more inclusive, discriminating, self-reflective, and integrative of experience" (p. 5).

At project conceptualization, it was assumed by the IEGC researchers (academics responsible for the research component of the IEGC project) that the clinical teams at the geriatric day hospitals were already practicing in a highly collaborative manner. Mellor, Hyer, and Howe [18] suggested that the term geriatrics is "practically synonymous with the notion of an interdisciplinary approach" (p. 868). This perception was supported by Burbank et al. [19] in their statement that, due to the heterogeneity of older adults and the complexity of care required, interdisciplinary clinical teams were the most effective manner in which to provide healthcare services. The IEGC researchers did not, therefore, design educational experiences for the clinical teams a priori. Geriatric day hospital clinical teams were asked to maintain their standard of practice, allowing for pre-licensure learners to observe collaborative behaviours and skills. As the project evolved, however, training opportunities arose and educational needs were identified by the clinical teams. 
Learning Through Teaching: Facilitating Interprofessional Education Experiences

Grymonpre, van Ineveld, Nelson, De Jaeger, Sullivan, Jensen, Weinberg, Swinamer, \& Booth

Journal of Research in Interprofessional Practice and Education

Vol. 1.3 December, 2010
Journal of Research in Interprofessional Practice and Education

At the onset of the program, the IEGC research team engaged in introductory discussions with each clinical team to determine what supports and materials each clinical team might require in order to foster and facilitate the educational program in their respective day hospitals. Information solicited from clinical teams included factors that were specific to each day hospital (scheduling, staffing, other clinical programs running out of the DH) that might impact or influence the IEGC schedule of activities.

Prior to the first IEGC clinical block offering, preceptors and clinical team members received a copy of the student education materials so they could become familiar with the pre-licensure learners' specific educational materials. The IEGC project also purchased a library of resources for each of the day hospitals (including texts and videos on interprofessional teaming). This same package of resources was also provided to the control site upon termination of the project.

Preceptors and clinical team members facilitating pre-licensure learner sessions were provided with a handbook containing background reading on the core competencies and detailed instructions for the conduct of each session. As well, individual coaching on facilitating small groups and providing feedback was offered to those team members who felt they had less experience and wanted additional coaching.

The Team Observation Scale (2003) was used as a reflective educational tool for the clinical teams; it allowed them to examine their team behaviours. Data documented from this activity were not part of the data analysis. The Team Observation Scale (TOS) was created by Cole, Waite, and Nichols [4] to be used as an observation tool with which to assess changes in teaming behaviour over time. A truncated version of this scale is currently implemented as part of the GITT core curriculum [20]. For the purposes of the present study, the TOS was operationalized by researchers to facilitate inter-observer reliability prior to implementation (with permission from the authors). This TOS was offered as an optional activity, with each intervention team twice at 6-month intervals. On each occasion, the same external observer attended the regular team care planning rounds, implemented the TOS, and discussed their observations with the clinical team members. This exercise was driven by clinical team members to reflect on their own practice in their own way, with no external facilitation or support.

Although no didactic education was directed solely at GDH clinical teams, formal presentations on educational topics related to IPE and CPCP were incorporated into various academic presentations. Geriatric Medicine Grand Rounds is widely advertised to the geriatrics community in Winnipeg and is open to all clinical team members in the day hospitals, regardless of participation in the IEGC program. Over the latter half of the project (June 2007 - January 2008), IEGC researchers presented three times in this forum. Topics included Goal Setting (CvI), Approaches to Teaching Collaboration (CvI, MN), and Conflict Management and Communication Strategies (JS, LW).

\section{Study participants}

Using purposeful sampling [21], three GDHs were asked to serve as intervention 
205

Learning Through Teaching: Facilitating Interprofessional Education Experiences

Grymonpre, van Ineveld, Nelson, De Jaeger, Sullivan, Jensen, Weinberg, Swinamer, \& Booth

Journal of Research in Interprofessional Practice and Education

Vol. 1.3

December, 2010 sites (sites A, B, and C), and one GDH was asked to serve as the control site (control). Participants were also recruited through purposive sampling, inviting only individuals who worked in the GDH. Information about project goals and procedures were presented to the clinical teams. Individual clinicians provided written informed consent if they agreed to participate in the IEGC study.

For the purposes of this study, any staff member of the GDH who had contact with the senior pre-licensure learners in any capacity was considered a clinical team member. All GDH staff (health, administrative, and support) were invited to participate in the IEGC study. Preceptors (discipline-specific mentors) were not distinguished from other members of the clinical team during data collection. Facilitators for the educational sessions were recruited at the beginning of each clinical placement and were considered eligible to facilitate if they did not have a student in the current placement.

\section{Study design}

The IEGC study implemented a concurrent mixed method design in which quantitative (controlled before and after) and qualitative data were collected and analyzed simultaneously to answer the overarching research question [21]. The mixed methods approach is advocated by Freeth et al. in their critical review of evaluations of IPE stating that "since most interprofessional education initiatives are multi-faceted, more mixed methods studies would be advantageous" [13, p. 55]. One recognized benefit of mixed method design is the concept of complementarity in that the data from one method clarifies or illustrates the results from the other method [21]. Data were collected concurrently; however, data sets were analyzed separately and were not compared until analysis of all data was completed. To explore the discrepancies between quantitative and qualitative findings, the researchers modeled an exploratory process after the one implemented by Moffatt et al. [22] regarding conflicting data in a mixed method study. These authors suggest six activities to explore discrepancies between quantitative and qualitative datasets: 1) treating the methods as different, 2) exploring the methodological rigour of each method, 3) exploring comparability of datasets, 4) collecting further data and making further comparisons, 5) exploring the intervention, and 6) exploring whether the outcomes of the two components matched. For this study, researchers addressed 4 of the 6 activities by: 1) assessing methodological rigour, 2) determining comparability of the quantitative and qualitative data, 3) examining the outcomes measured, and 4) exploring the intervention. Due to project timelines, collecting additional data was not possible. In retrospect, it was determined that quantitatively and qualitatively the methods were seeking to explore and explain different aspects of the research questions and that discrepancies between the data should have been expected.

\section{Mixed methods data collection and analyses}

Pre-IEGC experience data were collected from participating clinical team members (including controls) prior to the commencement of the first IEGC clinical block experience; post-IEGC testing took place upon completion of the IEGC program as 
206

Learning Through Teaching:

Facilitating Interprofessional Education Experiences

Grymonpre, van Ineveld, Nelson, De Jaeger, Sullivan, Jensen, Weinberg, Swinamer, \& Booth

Journal of Research in Interprofessional Practice and Education

Vol. 1.3 December, 2010 a whole. Participants were mailed testing materials and asked to return them to the IEGC office. Upon receipt of the completed test package in the IEGC office, participant honorariums were distributed.

Participants' attitudes and perceived skills and behaviours toward teaming in healthcare were assessed using the Geriatric Interdisciplinary Team Training (GITT) entry and exit questionnaires [20]. These questionnaires are a combination of both the Attitudes Toward Health Care Teams Scale (ATHCTS) [6] and the Team Skills Scale (TSS)[[23, 24] plus five additional questions specific to future learner recruitment and retention. The ATHCTS includes a 14-item Quality of Care (QoC) and a 7-item Physician Centrality (PC) subscale using a 6-point Likert scale and using both positively and negatively worded statements. For the Quality of Care subscale, a higher score indicates more positive attitudes toward teaming. For the Physician Centrality subscale, a lower score indicates a more positive attitude toward teams, assuming a more shared leadership in decision making. The TSS is a 17-item, 5-point Likert-type scale with values ranging from 1, "poor," to 5, "excellent"; summing the 17 items results in a score between 17 and 85. High scores are associated with positive perceptions of capabilities for effective team interactions. The TSS was designed to measure three factors: interpersonal skills, profession-specific skills, and geriatric care skills.

Previous research conducted in geriatric settings has shown the ATHCTS to be a reliable and valid measure of individual attitudes and perceived behaviours toward teaming. The Quality of Care and Physician Centrality subscales had Cronbach's alphas of .83 and .75, respectively, with item-to-total scale correlations ranging between .48 to .62 (Quality of Care) and .38 to .59 (Physician Centrality). Based on ratings by four experts, the Content Validity Index was .95 for appropriateness of items and .91 for assignment of items to domains [23-25]. Preliminary psychometric testing of the TSS suggests good reliability $[6,20]$. The TSS demonstrates good internal consistency reliability with a Cronbach's alpha of .94 and itemto-total scale correlation ranging form .58 to .78 . Face validity was determined using discussion and voting by clinical experts and educators who were asked to rank order the most important skills for geriatric healthcare professionals [24]. Both instruments have been used extensively by various GITT programs and were considered most appropriate for the present program of research and education in geriatric settings.

The IEGC Knowledge Questionnaire was created specifically for the IEGC program to assess if participants' knowledge regarding seven identified core competencies changed as a result of IEGC educational interventions. This 44-item knowledge test, consisting of true/false and multiple choice questions, was developed by the IEGC researchers to reflect the specific educational materials presented in the IEGC program. The instruments created specifically for the IEGC study are available on the Canadian Interprofessional Health Collaborative e-Library (www.cihc.ca/library).

At intervals of six months (four times over the course of the program), clinical team managers were asked to provide researchers with a "snapshot" of staffing levels and team structure. The IEGC Personnel Audit form was used as an ongoing 
207

Learning Through Teaching:

Facilitating

Interprofessional

Education

Experiences

Grymonpre, van

Ineveld, Nelson, De Jaeger, Sullivan, Jensen, Weinberg, Swinamer, \& Booth

Journal of Research in Interprofessional Practice and Education

Vol. 1.3

December, 2010 measure of clinical team personnel changes within and across each of the participating day hospital sites. The personnel audit included changes in Full Time Equivalent (FTE) appointments and profession-specific changes of clinical staff; it was also designed to measure organizational change.

Evaluation survey tools were created by the IEGC project team to collect quantitative and qualitative information regarding participants' reaction to the educational program, as well as any self-reported changes in knowledge, skills, attitudes, and behaviours. These formative evaluation data were collected in various ways. Immediately following each clinical block (11 in total), participating clinical team members completed an "experiential block evaluation form." These evaluation forms assessed perceived workload of the educational experience and asked for feedback on how to improve the education program for the next iteration. Also, at the end of each educational experience, researchers conducted feedback meetings with participating geriatric day hospital team members. These meetings provided clinical team members an opportunity to discuss the program in its entirety, including implementation, and to offer feedback regarding educational content as well as suggestions for future clinical experiences. Researchers kept field notes during each educational experience. These notes provided an opportunity to capture any observations and perspectives regarding the clinical learners that the researchers had during the implementation of the program. These notes were compiled and transcribed at the completion of each educational experience.

Summative evaluation occurred immediately upon completion of the entire IEGC program (January 2008), at which time participating preceptors/clinical team members were asked to complete final IEGC evaluation and self-reflective forms. These forms were designed to assess the participants' overall reaction to their IEGC experience and to collect participants' impressions about what influence the process had on their beliefs, perspectives, and assumptions about interprofessional teaming. The post-program evaluation was conducted with all participating clinical team members; it assessed general perspectives on the IEGC program, as well as what influence the program had on their clinical practice.

The IEGC Diary Sheet was developed to track any IEGC program-related activities participants were involved in and whenever a change in their typical activity occurred as a result of the program, for example, attending a lecture on interprofessional teaming, watching an interprofessional teaming video, etc. Diary sheets were made available to study participants in their team meeting room. The diary sheet was created by the IEGC research team specifically for the IEGC program, and it was intended to be used as an ongoing measure of behaviour change as well as changes in organizational practice.

The sample size calculation for the quantitative aspect of this project was based on a before/after and test/control comparison involving a 1:1 matched clinical team member sample (matched by discipline and clinical placement time), and the findings of one study where the Attitudes Toward Health Care Teams Scale was administered to health professionals [6]. The mean score for the 14-item Quality of Care/Process subscale administered to social workers was $57.5 \pm 8.2$. Assuming $80 \%$ 
208

Learning Through Teaching:

Facilitating Interprofessional Education Experiences

Grymonpre, van Ineveld, Nelson, De Jaeger, Sullivan, Jensen, Weinberg, Swinamer, \& Booth

Journal of Research in Interprofessional Practice and Education

Vol. 1.3

December, 2010 power, $\alpha=.05$, and a $10 \%$ change as significant, the required sample size was $N=40$ clinical team members per group (test and control). Our target over the 2 years of project implementation was 60 test clinical team members with 60 matched controls.

Quantitative data were entered into the Statistical Package for Social Sciences (SPSS) software [26]. Data analysis included descriptive, bi-variate, and repeated measures ANOVA (mixed modeling) procedures. The researchers used a mixed modeling procedure to allow for matching and comparisons across cohorts (test/control) and time (pre/post). Covariates thought to influence the study subjects' choice to participate (previous exposure to interprofessional training, gender, number of degrees) were documented and included in the analyses.

Field notes and open-ended responses to evaluation survey questions were analyzed using content analysis techniques to identify general categories or themes [21]. Open coding allowed the researchers to understand the scope of the information and present key themes with verbatim participant quotations. Themes were created to reflect the categories of information provided by participants. When possible, the researchers used the terminology (in vivo) of the participants as the code name. Over the course of the study, these codes were expanded based on additional information provided by participants. Researchers continually checked the data to ensure that the codes continued to accurately describe the perspectives of participants. Two researchers individually reviewed the material, generating codes. To ensure inter-rater reliability, the codes were then compared and content analysis techniques were conducted to determine frequency and patterns of codes.

\section{Results}

Mixed method results addressing findings for each of the Kirkpatrick's educational outcomes (reaction, changes in knowledge and skills, changes in attitudes/perceptions, self-reported behaviour, and organizational change) are presented.

Clinical team preceptors and staff were recruited in November 2005. Between January 2006 and March 2008, eleven interprofessional clinical placements (4 at sites $\mathrm{A}$ and $\mathrm{C}$ and 3 at site $\mathrm{B}$ ) were implemented involving 48 intervention and 16 control clinical team participants. Demographic data on the 32 intervention and 7 control clinical team study participants who completed both pre- and post-intervention surveys for at least one of the instruments are presented in Table 1. There were no baseline differences in gender, number of degrees, and prior IPE experience between the groups.

\section{Reaction}

When asked for quantitative and qualitative feedback on the IEGC program in general, a high proportion of the clinical team participants (70\%) felt that the IEGC project was a valuable experience, and $75 \%$ of respondents felt that other clinical programs would benefit from similar initiatives. In general, the day hospital clinical teams (70\%) were committed to continuing IEGC activities and furthering other IPE initiatives within the GDHs, noting, however, that the IEGC program was chal- 


\section{JRIPE}

209

Learning Through Teaching:

Facilitating Interprofessional Education Experiences

Grymonpre, van Ineveld, Nelson, De Jaeger, Sullivan, Jensen, Weinberg, Swinamer, \& Booth

lenging to implement. Only $35 \%$ of respondents disagreed when asked if the workload required to facilitate was excessive. Comments provided regarding the time required to facilitate the program focused on the time-consuming nature of program administration and coordination for clinicians and preceptors. These perceptions are exemplified by the following comments:

It was a good learning experience but time-consuming when you had to adjust work and client schedules in order to attend the meetings.

There needs to be someone to be in charge of the program - coordinate it as it is time-consuming for the preceptors who have the greatest involvement and time commitment.

Table 1

\section{Demographic data on clinical team preceptors and staff}

\begin{tabular}{|c|c|c|c|c|c|c|}
\hline & Site A & Site B & Site C & Control & Total & $P$-value \\
\hline & 12 & 10 & 10 & 7 & 39 & \\
\hline \multicolumn{7}{|l|}{ Gender } \\
\hline Male & 2 & 1 & 2 & 1 & 6 & .916 \\
\hline Female & 8 & 9 & 8 & 6 & 31 & \\
\hline No. degrees & & & & & & .631 \\
\hline 0 & 1 & 2 & 0 & 0 & 3 & \\
\hline 1 & 5 & 5 & 6 & 4 & 20 & \\
\hline 2 & 5 & 3 & 1 & 2 & 11 & \\
\hline 3 & 1 & 0 & 1 & 0 & 2 & \\
\hline Prior IPE & & & & & & .563 \\
\hline Yes & 7 & 5 & 5 & 6 & 23 & \\
\hline No & 5 & 4 & 2 & 1 & 12 & \\
\hline
\end{tabular}

Participants also provided additional open-ended comments regarding their experience with the IEGC program. These comments are encapsulated in two key themes: 1) the value of training for all professions and clinical programs and 2) the need for continuity and support of the educational program post funding. Participants emphasized the value of the education content by repeatedly identifying many other health professions that should be included in the IEGC program, and as one participant stated, "all professions should have teaming as part of their academic program (and) then practice this in a clinical setting."

Participants reported that they felt that the IEGC was a worthwhile learning pro-

Journal of Research in Interprofessional Practice and Education

Vol. 1.3

December, 2010 gram and that administrators should "make the program permanent! When a project works so well, it would be too bad if it is dropped due to lack of time by program (when commitment is there)." 


\section{JRIPE}

210

Learning Through Teaching:

Facilitating Interprofessional Education Experiences

Grymonpre, van Ineveld, Nelson, De Jaeger, Sullivan, Jensen, Weinberg, Swinamer, \& Booth
Journal of Research in Interprofessional Practice and Education

Vol. 1.3

December, 2010
Journal of Research in Interprofessional Practice and Education

Knowledge, skills, and attitudes

Table 2 outlines the results of the repeated ANOVA analyses. There was no significant change in the ATHCTS Quality of Care ( $\mathrm{p}=0.550)$ or the Physician Centrality $(p=.735)$ subscale scores over time for the combined intervention and control groups. There was also no significant difference in the change in these scores over time between intervention and control groups (QoC: $p=.390$; PC: $p=.521$ ). Differences over time remained non significant after controlling for prior IPE. Similarly, average scores between intervention and control groups were not significantly different (QoC: $p=.849$; PC: $p=.897$ ). There was also no significant difference in the change in the TSS and Knowledge scores over time (TSS: $p=.601$; Knowledge: $p=.365$ ), over time between intervention and control groups (TSS: $p=.713$; Knowledge: $p=.613$ ) or in the average scores (TSS: $p=.366$; Knowledge: $p=.689$ ) between intervention and control groups.

Table 2

Clinical team: ATHCTS, TSS \& Knowledge questionnaires: Intervention vs. control

$\begin{array}{lllll}\text { Pre-IEGCP } & \text { Post-IEGCP } & P \text {-value } & P \text {-value } & P \text {-value } \\ & & \text { Time effects } & \text { Time } x & \text { Average } x \\ & & \text { group effects } & \text { group effects }\end{array}$

\begin{tabular}{|c|c|c|c|c|c|}
\hline ATHCTS & Mean (SE $\left.{ }^{\mathrm{a}}\right)$ & Mean (SE) & & & \\
\hline \multicolumn{6}{|l|}{ Quality of Care } \\
\hline Intervention $(N=30)$ & $65.5(1.5)$ & $65.0(1.7)$ & .550 & .390 & .849 \\
\hline Control $(N=7)$ & $64.6(3.0)$ & $67.1(3.6)$ & & & \\
\hline \multicolumn{6}{|l|}{ Physician Centrality } \\
\hline Intervention $(N=30)$ & $7.5(0.7)$ & $7.8(1.0)$ & .735 & .521 & .897 \\
\hline Control $(N=7)$ & $8.3(1.4)$ & $7.4(2.0)$ & & & \\
\hline \multicolumn{6}{|l|}{ TSS } \\
\hline Intervention $(N=29)$ & $58.8(1.6)$ & $59.1(2.1)$ & .601 & .713 & .366 \\
\hline Control $(N=7)$ & $61.7(3.3)$ & $63.3(4.2)$ & & & \\
\hline \multicolumn{6}{|l|}{ Knowledge } \\
\hline Intervention $(N=31)$ & $23.1(1.6)$ & $24.1(0.7)$ & .365 & .613 & .689 \\
\hline Control $(N=7)$ & $22.9(1.4)$ & $23.1(0.7)$ & & & \\
\hline
\end{tabular}

\section{Behaviour}

Participants were asked to reflect any behaviour changes they experienced. When asked, "What are you doing now in your clinical work that you did not do before your participation in the IEGC program?" clinical team members' responses comprised three key themes: 1) more inclusive teaching and practice, 2) teaching IEGC principles, 3) more time spent on teaming and interprofessional interactions.

Several respondents indicated that as a result of participating in the IEGC project, they were more conscious of including IEGC materials and principles in their 
211

Learning Through Teaching:

Facilitating Interprofessional Education Experiences

Grymonpre, van Ineveld, Nelson, De Jaeger, Sullivan, Jensen, Weinberg, Swinamer, \& Booth

Journal of Research in Interprofessional Practice and Education

Vol. 1.3

December, 2010 clinical work and preceptorship, as one participant indicated, "I make more of a conscious effort to implement components of IEGC program." Another participant indicated that the program affected their work with other team members, "We are so busy doing our own tasks that we forget to be inclusive. I am now more cognizant of other team members."

Some participants indicated that they were more likely to ensure students from other professions were included in clinical team activities and that they had an opportunity to work with other professions in the GDH. To illustrate the shift to more inclusive teaching, one participant said, "I am ensuring students have time to meet with the other professionals on the team."

Several participants indicated that they spend more time working with students explicitly on team functioning and teaming skills, as one participant indicated, "I have spent more time with students talking about team function." Other clinical team members stated that they made more effort to work with students from other professions that they may not have had contact with traditionally. One participant noted their involvement with other students by stating: "I am providing more teaching to interprofessional students. I was always limited to teaching within my profession - nursing."

When clinical team members were asked, "In your opinion, how has your involvement in the IEGC program impacted your own teaming relationships?" participants were enthusiastic in stating that their involvement in the project had improved their own team relationships and dynamics. Participant responses fell within three themes: 1) increased confidence in their role on the team, 2) development of opportunities for reflection on their team, and 3) validation regarding the importance of teamwork.

Several participants indicated that their confidence had improved as a result of their participation, and one participant felt that they were "more confident in my opinion and speaking forward," during team care planning sessions.

Most participants indicated that they reflected on their own teaming skills and contribution to the team regularly, which also reflected their increased appreciation for the value of teamwork. Several participants' responses reflected these themes:

Having opportunity to have discussions with students re their views on team work made me evaluate my thoughts about team work and (how) I am currently functioning within my team.

I realize even more the importance of being a good communicator.

Made me more aware of why I am able to work better automatically with some team members vs. others, i.e., type A vs. Type B, flexible vs. rigid, or controlling vs. laid back.

More aware of other people's (team members) opinions if I don't agree right away; take time to put myself in their shoes.

I know my co-workers better; I think the lines of communication are improved/more efficient. 
212

Learning Through Teaching:

Facilitating Interprofessional Education Experiences

Grymonpre, van Ineveld, Nelson, De Jaeger, Sullivan, Jensen, Weinberg, Swinamer, \& Booth

Journal of Research in Interprofessional Practice and Education

Vol. 1.3

December, 2010

\section{Organizational changes}

Based on data from the IEGC personnel audit form, there were a small number of staffing changes at the GDH sites. However, staffing levels remained fairly stable, with only one clinical team member re-locating to a new position over the duration of the IEGC project. The IEGC Diary Sheets were not a successful data collection activity at the clinical sites, as only one diary sheet was received. Although clinicians indicated that they had changed their clinical practice as a result of their participation in the IEGC program (reported during the formative feedback meetings post clinical experience), they did not complete IEGC Diary Sheets to document these changes.

Also during the formative feedback meetings held with clinical team members post educational experience, researchers identified four pieces of valuable information that influenced the program design and implementation significantly. First, at the time of program design and implementation, clinical teams indicated that they wanted to be treated as a cohesive unit with all educational activities made available to interested day hospital staff regardless of profession or role. A second and very important piece of feedback centred on the team wanting to be more involved in the teaching of students on the topic of teamwork. Several clinical team members indicated they felt this fulfilled their mentorship role, and that it increased the likelihood of continuity. They believed that if clinical team members were versed and experienced in teaching that they would incorporate it into their regular preceptorship activities. Third, it was noted by researchers that each clinical team had their own procedures and practices, and that the IEGC program had to be responsive to the unique features of each site while maintaining consistency in educational content. Finally, it was observed that each clinical team had a unique organizational culture and perspective toward the IEGC program. This translated into widely varying views of the educational program; some sites were very excited to be part of training students in interprofessional teaming, while, conversely, some clinical team members suggested to researchers that they were already practicing and precepting students in teamwork, and that the formalized approach of the IEGC program was an additional responsibility that detracted from their already heavy clinical responsibilities.

The uptake of the Team Observation Process is an example of the varying perspectives of clinical teams. Although all teams were provided with the opportunity to engage in an external observer and feedback process as a team development activity, not all teams took full advantage of this opportunity. One team suggested, however, that they would continue to use the tool and the process as a mechanism of team reflection after the IEGC program was over.

\section{Discussion}

The IEGC program sought to utilize transformative learning theory as the foundation for the educational strategies for participating clinical team members. Clinical team members in this project engaged in reflection and identified their own learning needs. Although they were offered a range of educational opportunities, no formal education was specifically designed nor required, neither prior to nor during the IEGC study. 
Learning Through Teaching: Facilitating Interprofessional Education Experiences

Grymonpre, van Ineveld, Nelson, De Jaeger, Sullivan, Jensen, Weinberg, Swinamer, \& Booth

Journal of Research in Interprofessional Practice and Education

Vol. 1.3 December, 2010
After conducting separate analyses of the quantitative and qualitative datasets, a discrepancy in the findings became apparent. Using a Controlled Before and After (CBA) study design and quantitative analyses, there were no significant differences between intervention and control groups in knowledge, perceived skills, and attitudes toward teaming pre- versus post-participation in the IEGC project. Qualitative data collected in the IEGC project, however, did capture changes in attitude, team skills, and behaviour. Participants repeatedly indicated that they were more aware of interprofessional teaming, reflective of their own practice, and they reported making changes in their own practice and mentorship of students as a result of their engagement in the study. As both data sets were collected by the same researchers, at the same time, with the same participants, the researchers are confident that methodological issues were not the reason for discrepant results. Moffat et al. [22] suggest that the collection of additional data to allow for further comparisons may assist in determining reasons for discrepant data. Collecting additional data from the IEGC participants was not possible, due to study timelines. Future mixed method studies should plan for addressing the possibility of discrepant results early in the study design phase. As the quantitative and qualitative methods of the IEGC program were separate and distinct, each measuring different aspects of the phenomenon, it should not be surprising that discrepant results were obtained. This discrepancy supports the process of "treating qualitative and quantitative datasets as complementary rather than in competition for identifying the true version of events" [22, p. 9].

The lack of significant change in the quantitative ATHCTS or TSS of clinical team members pre- versus post-intervention was also noted in the Rhode Island Geriatric Education Centre (RIGEC) project [10], which used an uncontrolled study design despite a much more formal series of interprofessional training sessions. In addition to small sample sizes and high attrition, Clark attributes this lack of change to the high baseline scores of the clinical teams, which he postulates have reached "saturation" or a "plateau" in collaborative competencies. Clark found statistically significant $(p<.05)$ differences in the baseline ATHCTS across the 8 participating sites, with scores ranging between 128 and 148 [10]. Although significant differences were not found in baseline TSS scores in Clark's study, they ranged between 58 and 76, with two teams' mean scores falling below midpoint. Clark also noted variations in the team score standard deviations, suggesting a lack of consensus within teams. Our sample was not large enough to look at measures of between team variation, but qualitatively we observed variation and feel this is an area that warrants further study.

In contrast to the negative findings of the IEGC study, Morey et al. [26] did observe improvements in quality of team behaviours and attitudes toward teamwork. These authors conducted a quasi-experimental controlled study evaluating the impact of a formal team training curriculum for emergency department staff (albeit using different instruments: the validated Team Dimensions Rating Form, and the Staff Attitude and Opinion Survey, designed specifically for the project). This study illustrates the potential of mixed teaching methods (formal training, observation, and feedback in the practice context) to improve collaborative atti- 
214

Learning Through Teaching:

Facilitating Interprofessional Education Experiences

Grymonpre, van Ineveld, Nelson, De Jaeger, Sullivan, Jensen, Weinberg, Swinamer, \& Booth

Journal of Research in Interprofessional Practice and Education

Vol. 1.3

December, 2010 tudes and behaviours of team members [27]. The educational intervention used by Morey et al., an adapted version of Crew Resource Management methods, focused on behavioural change educational strategies in addition to traditional classroombased instruction. Similar to the educational activities of the IEGC program, Morey et al. included a post-training practicum involving opportunities to practice teamwork behaviours under observation for 4 hours and ongoing availability of coaching and mentoring.

Other evidence pointing to the value of observation and feedback is the work of Cox, Banez, Hawley, and Mostade [28], who conducted a study implementing two reflective exercises with teams of learners in a graduate-level training program. They concluded that the reflection process was a flexible way to examine group dynamics, as all of the interaction occurs within the context of the group. Learners in this study indicated the learning modality was particularly useful, as they were able to develop better awareness of group processes while maintaining engagement in the group. Hensley [29] implemented a "two-way fishbowl" method to teach group processes, whereby each participant had the opportunity to act as both an observer and a group participant. This process allowed participants to observe and appreciate the roles of their group members, view strengths and limitations of various leadership styles, and reflect on their own influence in the group.

The clinical team learners involved in the IEGC study participated in several reflective group activities, first as observers for student learner care planning exercises, and, second as participants being observed through the TOS process. Although data were not collected from participants pertaining specifically to the observation and reflection exercises, feedback received from clinicians at educational design meetings suggested that they felt this was an important aspect of the program. Further to this point, two of the participating clinical teams specifically requested further TOS sessions, indicating that they felt the sessions were valuable. One team indicated to the researchers that they intended to implement a team observation and reflection process in their weekly rounds. Cox et al. [28] noted that there was little work examining the benefits of using reflective team processes as a training exercise. Based on anecdotal feedback from clinical team learners the reflective group activities were noted to be a unique and successful component of the IEGC educational program. Further work specific to the value of team observation and reflection is recommended.

Variation in uptake/response to educational interventions across teams is not surprising given the multidimensional and complex constructs that influence team effectiveness. As aptly noted by Clark,

The actual process of developing and implementing training to promote teamwork is far more complex and complicated than is usually understood and acknowledged. At a more superficial level, team training as simply a focus on general group dynamics and issues internal to the team can yield a simplistic approach that is formulaic and "one size fits all" in nature. However, at a deeper level a recognition of the complexity of teamwork in the current healthcare sys- 
Learning Through Teaching: Facilitating Interprofessional Education Experiences

Grymonpre, van Ineveld, Nelson, De Jaeger, Sullivan, Jensen, Weinberg, Swinamer, \& Booth

Journal of Research in Interprofessional Practice and Education

Vol. 1.3 December, 2010
Journal of Research in Interprofessional Practice and Education

tem-with its constant external threats from resource-minded administrators-establishes a much more dynamic and complex model for teamwork training. [10, p. 492]

Reeves et al. [30] concur with this opinion in their environmental scan of literature related to interprofessional education, where they note the need to address several important planning and organizational factors specific to practice-based settings. Of particular relevance to the IEGC program is the concern noted by clinicians about clinical pressure in meeting multiple patient needs and the difficulty in finding time for the development and implementation of interprofessional education activities. The IEGC researchers had to navigate these issues with all of the participating day hospital clinical teams, senior management, and organizations. Researchers worked diligently with the teams to ensure that the educational program for students, and, subsequently, the clinical teams, was not an additional activity, but was aligned with existing clinical activities and other course expectations. Based on participants' feedback and researchers' experiences with the IEGC program, sustainability of the initiative would be dependent on a significant commitment on behalf of the organization and on change within existing teams' structures and processes.

This IEGC study was a small research study couched within a larger demonstration project. Investigators were, unfortunately, unable to recruit enough clinical team members to meet the power calculation sample size, which subjects the data to Type II error (i.e., false negative results). The investigators noted marked differences within and between the clinical sites; however, due to the small sample size, the investigators were unable to control for other potential confounders such as health profession, clinical practice site, and previous degrees. In addition to aspects of the educational intervention being voluntary and not linked to data collection activities, the study was also limited in that it was not a randomized controlled study, which may have led to participant selection bias.

\section{Conclusions}

Given our conflicting qualitative and quantitative findings, we must conclude that this study neither supports nor disputes the utility of transformative learning theory as a guiding framework for educating clinicians. Qualitative findings support the unique model of training used in this study such as reflective learning opportunities, implementing structured observation and feedback, and having opportunities for teaching pre-licensure learners as the impetus for clinical team member behaviour change, and point to areas requiring future research in the area of interprofessional teaming. Further research is required to address the concerns of heterogeneity across studies and the lack of scientific rigour raised by Reeves [30]. Continued research in this area will help to identify key approaches and elements to an effective IPE intervention for pre- and post-licensure learners in clinical practice.

\section{Acknowledgements}

The authors would like to acknowledge Riverview Health Centre for their generous 
216

Learning Through Teaching:

Facilitating Interprofessional

Education

Experiences

Grymonpre, van Ineveld, Nelson, De Jaeger, Sullivan, Jensen, Weinberg, Swinamer, \& Booth

Journal of Research in Interprofessional Practice and Education

Vol. 1.3

December, 2010 offering of institutional support, the Geriatric Day Hospital Teams for their support of this project, learners for their willingness to serve as intervention and control participants, and day hospital patients for their participation. The diligence and dedication of our communications manager Rachel Ines is also recognized. We would also like to thank Health Canada through the Health Human Resource (HHR) Strategy Interprofessional Education for Collaborative Patient Centred Practice (IECPCP) Initiative for their support of this project through a grant.

\section{Notes}

1. Clinical Placements refer to courses/learning opportunities that offer "real world" patient-/clientcentred health/social care learning opportunities for senior students-also known as clinical practicum, experiential learning, externship, and fieldwork. For the purpose of this study, the term clinical placement was used to encompass all the aforementioned terms.

2. Senior pre-licensure learner is the term used to describe students in the final year of study of their respective programs who have not yet obtained their licensure to practice. This included undergraduate students in pharmacy, nursing, and physical therapy; graduate students in occupational therapy; and post-graduate students in medicine (residents).

\section{References}

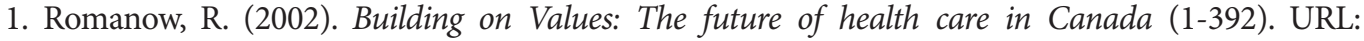

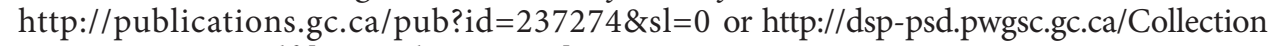
LCP 32-85-2002E.pdfi [November 2, 2010].

2. Health_Human Resource Strategy. (2006). URL: 'htttp://wwww.hc-sc.gc.ca/hcs-sss/hhr-rhs '/index-eng.phpi' [November 2, 2010].

3. Barr, H. (2002). Interprofessional education today, tomorrow and yesterday. The Learning and Teaching Support Network for Health Sciences \& Practice from The UK Centre for the Advancement of Interprofessional Education (CAIPE), 1-47.

4. Cole, K.D., M.S. Waite, \& Nichols, L.O. (2003). Organizational structure, team process, and future directions of interprofessional health care teams. Gerontology \& Geriatrics Education, 24(2), 35-49.

5. Hyer, K. et al.(2003). Using scripted video to assess interdisciplinary team effectiveness training outcomes. Gerontology \& Geriatrics Education, 24(2), 75-91.

6. Heinemann, G.D., et al. (1999). Development of an attitudes toward health care teams scale. Evaluation \& the Health Professions 22(1), 123-142.

7. Fulmer, T., Flaherty, E., \& Hyer, K. (2003). The geriatric interdisciplinary team training program (GITT). Gerontology \& Geriatrics Education, 24(2), 3-12.

8. Flaherty, E., et al. (2003). Using case studies to evaluate students' ability to develop a geriatric interdisciplinary care plan. Gerontology \& Geriatrics Education, 24(2), 63-74.

9. Dyer, C., et al. (2003). Frail older patient care by interdisciplinary teams: A primer for generalists. Gerontology \& Geriatrics Education, 24(2), 51-62.

10. Clark, P., Leinhaas, M., \& Filinson, R. (2002). Developing and evaluating an interdisciplinary clinical team training program: Lessons taught and lessons learned. Educational Gerontology, 28, 491-510.

11. Hammick, M., et al. (2005). Reviewing the Evidence Base. In Barr, H. (Ed.), Effective Interprofessional Education: Argument, Assumption \& Evidence (pp. 40-47). Blackwell Publishing Ltd: Oxford.

12. Reeves, S., et al. (2008). Interprofessional education: effects on professional practice and health care outcomes. Cochrane database of systematic reviews, 1(1), online, CD002213.

13. Freeth, D., et al. (2002). A critical review of evaluations if interprofessional education. CAIPE - UK Centre for the Advancement of Interprofessional Education: London.

14. Grymonpre, R.E., van Ineveld K., Nelson, M., Jensen, F., De Jaeger, A., Sullivan, T., Weinberg, L., Swinamer, J., \& Booth, A. (2010). See It - Do It - Learn It: Learning Interprofessional Collaboration in the Clinical Context. Journal of Research in Interprofessional Practice and Education, 1(2), 127-144.

15. Barr, H. (1998). Competent to collaborate: Towards a competency-based model for interprofessional education. Journal of Interprofessional Care, 12(2), 181-187. 


\section{JRIPE}

\section{7}

Learning Through Teaching:

Facilitating Interprofessional Education Experiences

Grymonpre, van Ineveld, Nelson, De Jaeger, Sullivan, Jensen, Weinberg, Swinamer, \& Booth

\section{Journal of Research in Interprofessional Practice and Education}

16. Curran, V. (2005). Interprofessional Education for Collaborative Patient-Centred Practice Research Synthesis Paper. Ottawa, ON: Health Canada.

17. Mezirow, J. \& Cranton, P. (1997). Transformative Learning: Theory to Practice, in Transformative Learning in Action: Insights from Practice. New Directions for Adult and Continuing Education, No. 74, 5-12. San Francisco, CA: Jossey-Bass.

18. Mellor, M., Hyer, K. \& Howe, J. (2002). The geriatric interdisciplinary team approach: Challenges and opportunities in educating trainees together from a variety of disciplines. Educational Gerontology, 28, 867-880.

19. Burbank, P., et al. (2002). Developing an interdisciplinary geriatric curriculum: The perils and payoffs of collaboration. Educational Gerontology, 28, 451-472.

20. Hyer, K., et al. (2003). Geriatric Interdisciplinary Team Training: The GITT Kit, (2nd Edition). New York.: John A. Hartford Foundation, Inc.

21. Creswell, J.W. (2003). Research design: Qualitative, quantitative, and mixed method approaches. Thousand Oaks CA: Sage Publications Inc.

22. Moffatt, S., et al. (2006). Using quantitative and qualitative data in health services research - what happens when mixed method findings conflict? [ISRCTN61522618]. BMC Health Services Research, 6(1), 28.

23. Sigler, E. L., et al. (1998). Team Skills Scale. In Hepburn, K. et al, Geriatric Interdisciplinary Team Training (p. 264-265). New York: Springer Publishing Company.

24. Hepburn, K., Tsukuda R.A., \& Fasser, C. (2002). Team Skills Scale. In G.D. Heinemann \& A.M. Zeiss, (Eds.), Team Performance in Health Care: Assessment and Development (pp. 159-163). New York, NY: Kluwer Academic/Plenum Publishers.

25. Heinemann, G.D., Schmitt, M.H., Farrell, M.P. (2002). Attitudes Toward Health Care Teams. In G.D. Heinemann \& A. M. Zeiss, (Eds.), Team Performance in Health Care: Assessment and Development (pp. 255-159). New York, NY: Kluwer Academic/Plenum Publishers.

26. Statistical Package for Social Sciences Advanced Models. (2007). Chicago, IL: SPSS Inc.

27. Morey, J.C., et al. (2002). Error reduction and performance improvement in the emergency department through formal teamwork training: evaluation results of the MedTeams project. HSR: Health Services Research, 37(6), 1553-1581.

28. Cox, J.A., et al. (2003). Use of the Reflecting Team Process in the Training of Group Workers. The Journal for Specialists in Group Work, 28(2), 89-105.

29. Hensley, L.G. (2002). Teaching Group Process and Leadership: The Two-Way Fishbowl Model. The Journal for Specialists in Group Work, 27(3), 273-286.

30. Reeves, S., et al. (2008). An Environmental Scan and Literature Review on Interprofessional Practice Settings: Final Report for Health Canada. University of Toronto, ON: La Ka Shing Knowledge Institute of St. Michael's Hospital.

Journal of Research in Interprofessional Practice and

Education

Vol. 1.3

December, 2010 